L.). The effect on corolla size of the hypothetical anther hormone of Glechoma is evidently quite localized sinee small female and large hermaphrodite flowers occur close together in the same inflorescence. However, it was not found possible to destroy the symmetry of the corolla by removing two anthers asymmetrically.

In conclusion, it seems to me that the reduction in size of the pistillate flowers is a secondary sexual characteristic, resulting directly from the loss of the anthers, and not necessarily connected in any more immediate way with the factors which determine the sex of the flowers.

I am much indebted to Prof. D. Lewis for helpful discussion.

Dept. of Biology,

Audrey Prack

University College of North Staffordshire, Keele, Staffs. Oct. 15.

2 Baker, H. G., Nature, 180, 614 (1957).

${ }^{2}$ Wittwer, S. H., Univ. of Missouri Coll. of Agric. Res. Bull. 371 (1943).

\section{Germinating Spores in the Rhynie Chert}

A SMaLL loose block of Rhynio Chert (Scottish Middle Old Red Sandstone) has been found to contain a number of isolated spores which appear to have been germinating at the time when the onset of conditions favouring their preservation occurred. In some cases it is elear that development had only just commenced, the spores having split open and produced small sac-like outgrowths in which no evidence of structure can be distinguished (Fig. la). A few specimens have been obtained, however, which probably represent slightly later stages, and in some of these, the outgrowths seem to be composed of thinwalled cells, although the possibility cannot be entirely excluded that they may be merely artefacts resulting from shrinkage or re-arrangement. The largest and best-preserved specimen found so far has an overall length of about $0.5 \mathrm{~mm}$., the distal end of the rather narrow outgrowth showing a clearly defined multicellular pattern although this can be recognized discontinuously to the basal portion where it emerges from the spore. Owing to its obliquity in the matrix, it has not proved possible to obtain a satisfactory photograph, but its form is generally similar to that of the specimen shown in Fig. $\mathbf{l} b$. While the outgrowth in this case is slightly smaller and rather badly decayed, the tripartite splitting of the spore is clearly visible. Another specimen showing this feature together with evidence of possible cellular structure appears as Fig. 1c, part of the (? incomplete) outgrowth being shown at a higher magnification in Fig. $1 d$.

While there can be no cortainty regarding the identities of any of the spores, size measurements, takon in conjunction with the recorded flora of the deposit ${ }^{1}$, make it not unlikely that some of them, at loast, may have been the products of one of the known vascular plants. A few spores, the maximum diameter of which prior to splitting has been estimated at about $67 \mu$, compare fairly closely both in size and

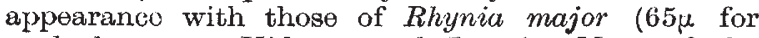
unshed sporos, Kidston and Lang1). Most of the spores showing evidence of development, however, although generally similar in form to those of Rhynia, aro appreciably larger, being about $81 \mu$ in diameter. While there is evidence to suggest that these were formed in tetrads, the plant which produced them is as yet unknown. $a$

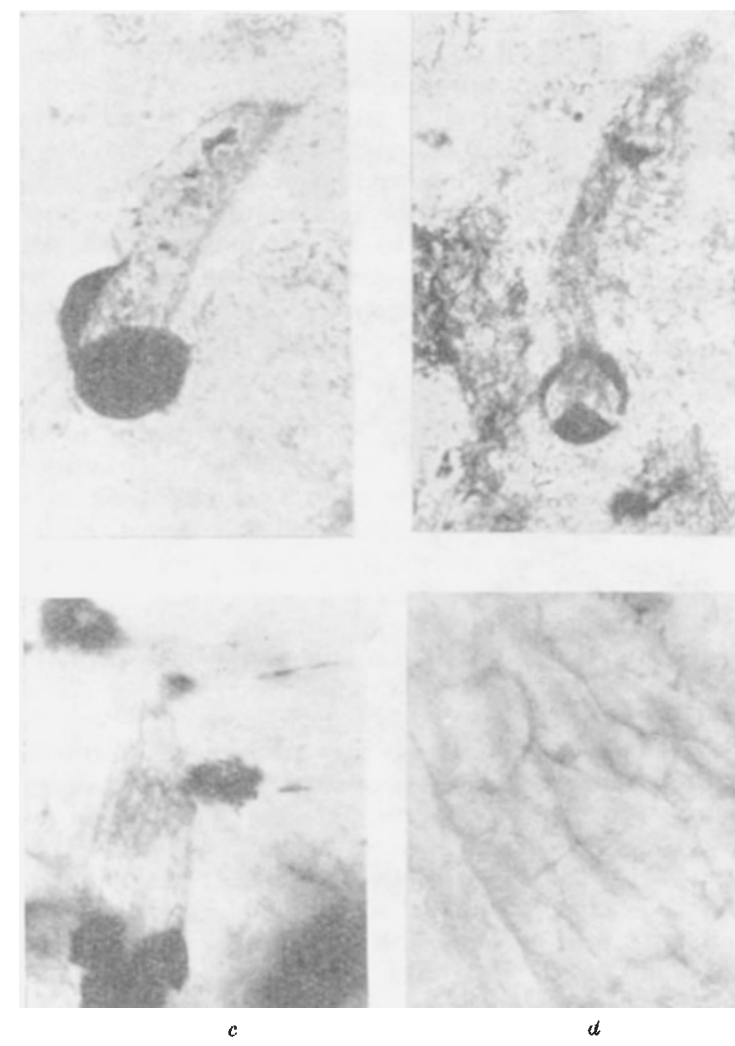

Fig. 1. $a$, Germinating spore (? of Rhynia major) ( $\times$ c. 190); $b$, spore of similar size with more extensive outgrowth $(x$ c. 98$)$ $c$, spore estimated to be about $81 \mu$ in diameter with outgrowth $(\times c .95) ; d$, part of the above outgrowth showing evidence of possible cellular structure $(\times c .375)$. All figures are reproduced
from untouched photographs

Associated with the spores in the block are abundant fragmentary remains of Algites (Palaeonitella) cranii the occurrence of which, at certain levels in the deposit, has been interpreted by Kidston and Lang assuggesting the existence of highly aquatic and probably submerged conditions. There are no certain means of knowing, however, whether it was under such condi. tions that germination took place or whether the spores, having germinated elsewhere, were carried into the positions which they finally occupied during a period of inundation at a late stage prior to petrifaction.

It seems reasonable to suppose that the outgrowths represent early stages in the development of the gametophyte generation of certain Middle Devonian plants, some, if not all, of which may well have been Psilophytes. While those found up to the present have been, at the best, imperfectly preserved and of uncertain identity, their presence in the chert increases the hope that something may yet be known of the adult prothallia of the early land plants of the Rhynio deposit.

A fuller account may be published elsewhere, when the examination of the remaining material has been comploted.

Department of Botany,

University College,

Cardiff. July 20.

${ }^{1}$ Kidston, R., and Lang, W. H., Trans. Roy. Soc. Edin., 51, 2 (1917-21). 